\title{
Selective Blockade of the Capsaicin Receptor TRPV1 Attenuates Bone Cancer Pain
}

\author{
Joseph R. Ghilardi, ${ }^{1,2}$ Heidi Röhrich, ${ }^{1}$ Theodore H. Lindsay, ${ }^{1}$ Molly A. Sevcik, ${ }^{1}$ Matthew J. Schwei, ${ }^{1}$ Kazufumi Kubota, ${ }^{1}$ \\ Kyle G. Halvorson, ${ }^{1}$ Jeannie Poblete, ${ }^{4}$ Sandra R. Chaplan, ${ }^{5}$ Adrienne E. Dubin, ${ }^{5}$ Nicholas I. Carruthers, ${ }^{5}$ Devin Swanson, ${ }^{5}$ \\ Michael Kuskowski, ${ }^{3}$ Christopher M. Flores, ${ }^{6}$ David Julius, ${ }^{4}$ and Patrick W. Mantyh ${ }^{1,2}$ \\ ${ }^{1}$ Neurosystems Center and Departments of Preventive Sciences, Psychiatry, Neuroscience, and Cancer Center, University of Minnesota, Minneapolis, \\ Minnesota 55455, ${ }^{2}$ Research Service and ${ }^{3}$ Geriatric Research, Education, and Clinical Center, Veterans Affairs Medical Center, Minneapolis, Minnesota \\ 55417, ${ }^{4}$ Department of Cellular and Molecular Pharmacology, University of California, San Francisco, San Francisco, California 94143-2140, ${ }^{5}$ Johnson and \\ Johnson Pharmaceutical Research and Development, San Diego, California 92121, and ${ }^{6} J o h n s o n$ and Johnson Pharmaceutical Research and Development, \\ Spring House, Pennsylvania 19446
}

Cancer colonization of bone leads to the activation of osteoclasts, thereby producing local tissue acidosis and bone resorption. This process may contribute to the generation of both ongoing and movement-evoked pain, resulting from the activation of sensory neurons that detect noxious stimuli (nociceptors). The capsaicin receptor TRPV1 (transient receptor potential vanilloid subtype 1) is a cation channel expressed by nociceptors that detects multiple pain-producing stimuli, including noxious heat and extracellular protons, raising the possibility that it is an important mediator of bone cancer pain via its capacity to detect osteoclast- and tumor-mediated tissue acidosis. Here, we show that TRPV1 is present on sensory neuron fibers that innervate the mouse femur and that, in an in vivo model of bone cancer pain, acute or chronic administration of a TRPV1 antagonist or disruption of the TRPV1 gene results in a significant attenuation of both ongoing and movement-evoked nocifensive behaviors. Administration of the antagonist had similar efficacy in reducing early, moderate, and severe pain-related responses, suggesting that TRPV1 may be a novel target for pharmacological treatment of chronic pain states associated with bone cancer metastasis.

Key words: tumor; skeletal malignancies; vanilloid receptor; metastasis; nociception; therapy

\section{Introduction}

Cancer pain is a significant clinical problem because it is the first symptom of disease in $20-50 \%$ of all cancer patients and $75-90 \%$ of advanced or terminal cancer patients must cope with chronic pain syndromes related to failed treatment and/or tumor progression (Mercadante and Arcuri, 1998; Portenoy et al., 1999). Malignant bone tumors occur in patients with primary bone cancer but far more commonly occur as distant metastases of nonbone primary tumors, notably those in breast, prostate, and lung. As such, bone is the most common site of origin of chronic pain in patients with metastatic lung, prostate, and breast cancers or myeloma (Coleman, 1997, 2001). Osteoclasts, the body's principal bone-resorbing cells, have been implicated recently in bone cancer pain (Adami, 1997). The mechanisms underlying attenuation of bone cancer pain after inhibition of osteoclast activity may include reduction of osteoclast-induced mechanical defor-

Received Sept. 14, 2004; revised Feb. 1, 2005; accepted Feb. 1, 2005.

This work was supported by National Institutes of Health Grants NS23970 (P.W.M.), DA11986 (P.W.M.), and DE08973 (D.J.), a Veterans Affairs Merit Review (P.W.M.), and a research grant from Johnson and Johnson Pharmaceutical Research and Development.

Correspondence should be addressed to Patrick W. Mantyh, Neurosystems Center, 18-208 Moos Tower, School of Dentistry, University of Minnesota, 515 Delaware Street Southeast, Minneapolis, MN 55455. E-mail: manty001@umn.edu.

DOI:10.1523/JNEUROSCI.3815-04.2005

Copyright $\odot 2005$ Society for Neuroscience $\quad 0270-6474 / 05 / 253126-\bullet \$ 15.00 / 0$ mation of bone and/or local tissue acidosis. Osteoclast-mediated bone remodeling is also accompanied by the robust production of extracellular protons, which are known to be potent activators of primary afferent neurons (Krishtal and Pidoplichko, 1980; Bevan and Geppetti, 1994; Reeh and Steen, 1996), raising the possibility that the acidic microenvironment produced by osteoclasts contributes significantly to bone cancer-associated pain via activation of acid-sensitive nociceptors that innervate the marrow and mineralized bone.

Tissue acidosis may activate nociceptors via multiple molecular mechanisms, but one important site of proton action is the capsaicin receptor TRPV1 (transient receptor potential vanilloid subtype 1), a heat- and proton-activated ion channel that is located on primary afferent sensory neurons (Caterina et al., 1997; Tominaga et al., 1998). Acid ( $\mathrm{pH}$ 5)-evoked excitatory responses are greatly reduced in sensory neurons from TRPV1-deficient mice (Caterina et al., 2000; Davis et al., 2000), substantiating a role for this ion channel in the detection of extracellular protons in vivo. Moreover, TRPV $1^{-1-}$ animals show impaired thermal hypersensitivity in response to tissue inflammation (Caterina et al., 2000; Davis et al., 2000), supporting the idea that TRPV1 serves as a detector of injury-induced chemical stimuli that excite primary afferent nociceptors or sensitize their response to heat (Tominaga et al., 1998). In light of the clinical significance and severity of bone cancer pain and the potential relevance of tissue 

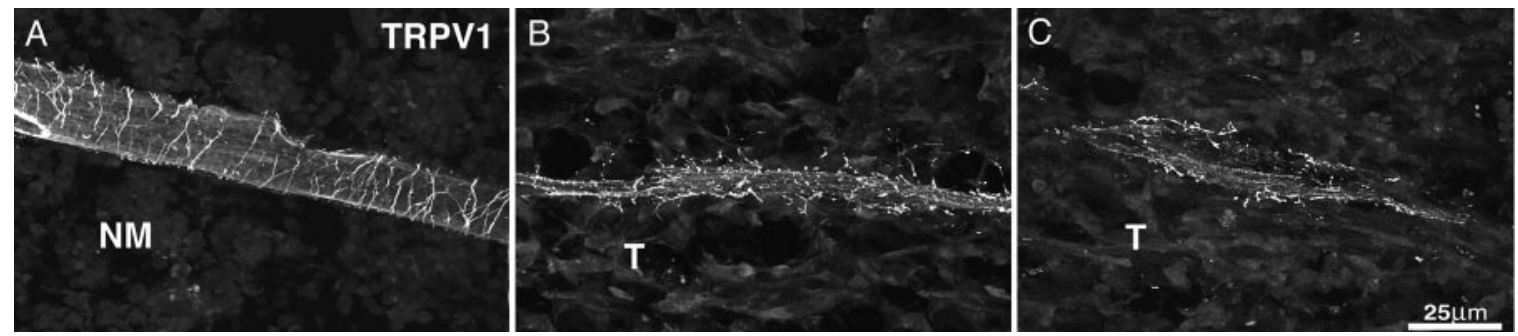

Figure 1. A subpopulation of sensory nerve fibers that innervate the bone express the TRPV1 channel. Confocal photomicrographs showing TRPV1-expressing nerve fibers in the normal and tumor-bearing bone. $A$, In the marrow space of the normal bone, TRPV1-expressing nerve fibers are closely associated with blood vessels similar to observations in other peripheral vascular beds. $B$, After tumor invasion of the marrow space, TRPV1-expressing sensory fibers remain associated with blood vessels at the leading edge of the tumor, but these fibers are not as ramified as those found in the normal bone. C, As tumor growth continues, TRPV1-expressing fibers can still be found deep within the tumor, but, in general, the fibers begin to have a fragmented appearance, suggesting tumor-induced destruction of the distal processes of the sensory nerve fibers. NM, Normal marrow; T, tumor. $\boldsymbol{B}$, Leading edge. $\boldsymbol{C}$, Major body of tumor mass.

acidosis to this process, we examined the involvement of TRPV1 and the effectiveness of a TRPV1 antagonist in attenuating bone cancer-induced hyperalgesia in a mouse model that closely mirrors the human condition.

\section{Materials and Methods}

Induction of bone cancer. Experiments were performed on adult (25-30 g) male $\mathrm{C} 3 \mathrm{H} / \mathrm{HeJ}$ mice (The Jackson Laboratory, Bar Harbor, $\mathrm{ME}$ ) and TRPV1 wild-type $(+/+)$ or mutant $(+/-,-/-)$ mice, which were maintained at $22^{\circ} \mathrm{C}$ with a $12 \mathrm{~h}$ light/dark cycle and given food and water ad libitum. The mice were housed in accordance with National Institutes of Health guidelines, and all procedures were approved by the Animal Care and Use Committee of the University of Minnesota. Injection of 2472 osteolytic sarcoma cells was performed as described previously (Luger et al., 2001).

Generation of TRPV1 null mice. TRPV1 heterozygotes $(+/-)$ on a C57BL/6 background (Caterina et al., 2000) were mated with $\mathrm{C} 3 \mathrm{H} / \mathrm{HeJ}$ mice and backcrossed until the fourth generation was reached, at which time 2472 cells grew and induced bone destruction and pain-related behaviors to a similar extent as that seen in $\mathrm{C} 3 \mathrm{H} / \mathrm{HeJ}$ mice. All of the animals used in the study were from the fourth generation or later. There were no statistically significant behavioral differences between the TRPV $^{+/+}$and the TRPV1 ${ }^{+/-}$animals; therefore, TRPV1 ${ }^{+/+}$animals were used as controls for all studies.

Treatment with the TRPV1 antagonist. To assess the effect of a TRPV1 receptor antagonist (JNJ-17203212) on bone cancer pain-related behaviors, tumor growth, and bone destruction, animals were chronically treated with $30 \mathrm{mg} / \mathrm{kg} \mathrm{JNJ}-17203212$ dissolved in $120 \mu \mathrm{l}$ of Solutol and $680 \mu \mathrm{l}$ of $5 \%$ dextrose twice daily subcutaneously or an equivalent volume of vehicle alone. Previous studies have shown that JNJ-17203212 is a selective, potent antagonist of both rodent and human TRPV1 (Dax et al., 2002) exhibiting an $\mathrm{IC}_{50}$ value of $38 \pm 10 \mathrm{~nm}$ (mean $\left.\pm \mathrm{SEM} ; n=4\right)$, comparable with its $K_{\mathrm{i}}$ value $(27 \pm 3 \mathrm{nM}$ ) for inhibiting capsaicin-evoked responses in transfected human embryonic kidney 293 cells. Treatment was initiated $6 \mathrm{~d}$ after injection, when observable bone destruction was evident, and was terminated at 14 or $18 \mathrm{~d}$ after injection, when there was significant bone destruction and hyperalgesia. The doses used in the current study caused no observable adverse effects in the animals in rotarod performance, general activity, and body weight. $\mathrm{C} 3 \mathrm{H} / \mathrm{HeJ}$ animals were given $30 \mathrm{mg} / \mathrm{kg}$ JNJ-17203212 subcutaneously twice daily for chronic studies, and, to assess the specificity of acute administration of JNJ-17203212, both TRPV $1^{+/+}$and TRPV1 ${ }^{-/-}$animals were given 30 $\mathrm{mg} / \mathrm{kg}$ JNJ-17203212 subcutaneously once $1 \mathrm{~h}$ before behavioral testing (see Fig. $3 E, F$ ).

Behavioral analysis. $\mathrm{C} 3 \mathrm{H} / \mathrm{HeJ}$ and TRPV1 wild-type $(+/+)$ and TRPV1 mutant $(+/-,-/-)$ mice were tested for pain-related behaviors both 10 and $14 \mathrm{~d}$ after sarcoma or sham injections, when pain-related behaviors are significantly evident. $\mathrm{C} 3 \mathrm{H} / \mathrm{HeJ}$ animals were tested 9, 11, 15 , and $18 \mathrm{~d}$ after tumor or sham injections to assess efficacy of the TRPV1 antagonist JNJ-17203212 over the progression of the disease, and ongoing and movement-evoked pain-related behaviors were analyzed as described previously (Luger et al., 2001). Ongoing nocifensive behaviors were evaluated by measuring spontaneous guarding and spontaneous flinching over a 2 min observation period, and movement-evoked allodynia was assessed by measuring the time spent guarding and flinching over a 2 min observation period after normally non-noxious palpation of the distal femur. The number of flinches was defined as lifting the tumorinjected limb while stationary, and time spent guarding was defined as the length of time the tumor-injected limb was held aloft. All of the behavioral data were obtained using at least eight animals for each time point or group, with the exception of the sarcoma-injected $\mathrm{C} 3 \mathrm{H} / \mathrm{HeJ}$ group $(n=4)$, which received the TRPV1 antagonist JNJ-17203212.

Euthanasia, processing of tissue, and immunohistochemical analysis of neural and bone tissues. Fourteen days after sarcoma injection, mice were killed, and serum and tissues were collected for analysis. To induce c-Fos expression, animals received a normally non-noxious palpation of the ipsilateral knee 90 min before being killed (Hunt et al., 1987; Honore et al., 2000a) and were subsequently processed for immunohistochemical analysis (Luger et al., 2001) using the following primary antibodies: guinea pig anti-mouse TRPV1 (1:5000; from the laboratory of D. Julius), rabbit anti-human activated transcription factor-3 (ATF-3) (1:500; Santa Cruz Biotechnology, Santa Cruz, CA), polyclonal rabbit anti-c-Fos (1: 15,000; Oncogene Research, San Diego, CA), and polyclonal rabbit anticalcitonin gene-related protein (CGRP) (1:45,000; Sigma, St. Louis, $\mathrm{MO})$. Spinal cords and DRGs were analyzed by conventional fluorescent and confocal microscopy, and quantification was performed as described previously (Schwei et al., 1999; Honore et al., 2000b). Tumor burden, bone destruction, and bone immunohistochemistry were processed and analyzed as described previously (Mach et al., 2002; Sabino et al., 2002). The anti-TRPV1 antibody was tested in TRPV $1^{-1-}$ mice, and no specific labeling was observed in DRG or femur.

Statistical analysis. The StatView statistics package (SAS Institute, Cary, NC) was used to perform statistical tests. One-way ANOVA was used to analyze behavioral results, bone histology results, and immunohistochemical measures among the experimental groups at each time point. Because of the increased risk of type I error associated with ANOVA at each of several time points, significance level was set at $p<$ 0.01. Significant individual ANOVA results were followed by post hoc between-group comparisons (Fisher's PLSD), with significance level set at $p<0.05$. The individual investigators responsible for bonedestruction scoring, behavioral testing, and immunohistochemical quantification were blinded to the experimental situation, including the genotype of each animal.

\section{Results}

\section{TRPV1 expression by sensory neurons that innervate}

\section{the femur}

TRPV1-expressing sensory fibers were present in mineralized bone and bone marrow, in which they were generally seen in close association with blood vessels and had a similar appearance to other sensory fibers, such as those that express CGRP and innervate the bone (Fig. $1 A$ ). At the leading edge of the tumor, sensory 
fibers continued to exhibit TRPV1 immunoreactivity (Fig. $1 B$ ). As the tumor cells filled the intramedullary space of the tumor, $20-25 \%$ of the sensory neurons in the L2 DRG expressed ATF-3, and $\sim 30 \%$ of these ATF-3-expressing neurons also exhibited TRPV1 immunoreactivity (Fig. 2E,F). These results suggest that a significant percentage of sensory neurons that innervate the tumor-bearing bone express TRPV1 and that TRPV1 expression is maintained even as the distal processes of these sensory fibers are injured by the invading tumor cells and induce ATF-3 expression.

TRPV1 antagonist-treated and TRPV1 null animals show reduced ongoing and movement-evoked pain-related behaviors and attenuation of spinal cFos expression

Chronic treatment of tumor-bearing animals with JNJ-17203212 resulted in decreased ongoing and movement-evoked nocifensive behaviors at days 10 and 14 after tumor injection (Fig. $3 A-D$, day 14) without any observable behavioral side effects, such as ataxia or hypoactivity. Similar results were observed when the same animals were analyzed 9, 11, 15, and $18 \mathrm{~d}$ after tumor injection. In both the acute and chronic administration protocols, there was no loss of efficacy of JNJ17203212 in reducing ongoing and movement-evoked nocifensive behaviors with disease progression (Fig. 3E,F).

Blockade of TRPV1 also prevented immediate-early gene activation attributable to a painful stimulus. Normally nonnoxious palpation induces significant ipsilateral c-Fos expression in laminas I-II of the L3/L4 spinal cord segment $14 \mathrm{~d}$ after tumor injection into the femur when compared with naive or sham animals (Schwei et al., 1999). This increase in laminas I-II c-Fos expression in vehicle-treated animals [17.5 \pm 4.0 c-Fos-immunoreactive (IR) neurons/L4 section] was significantly attenuated by chronic TRPV1 antagonist treatment [7.5 $\pm 3.2 \mathrm{c}$-Fos-IR neurons/(L3/ L4) section; $n=6$; data not shown]. TRPV1 expression was not detected in the sarcoma cells, and JNJ-17203212 did not significantly affect tumor growth, as quantitatively determined by hematoxylin and eosin staining and radiographic analysis of total tumor burden within the intramedullary space of the sarcomabearing femur.

The TRPV $1^{+/+}$and TRPV1 ${ }^{+/-}$animals showed the normal development of pain-related behaviors, whereas TRPV1 ${ }^{-1-}$ mice showed a significant reduction in both ongoing and movementevoked nocifensive behaviors similar to that observed in $\mathrm{C} 3 \mathrm{H} / \mathrm{HeJ}$ animals treated with JNJ-17203212. Moreover, no additional reduction in bone cancer pain-related behaviors was observed in TRPV1 ${ }^{-1-}$ animals receiving JNJ-17203212, suggesting that the major target for the analgesic action of JNJ-17203212 in this model of bone cancer pain is indeed the TRPV1 channel (Fig. 4A,B).
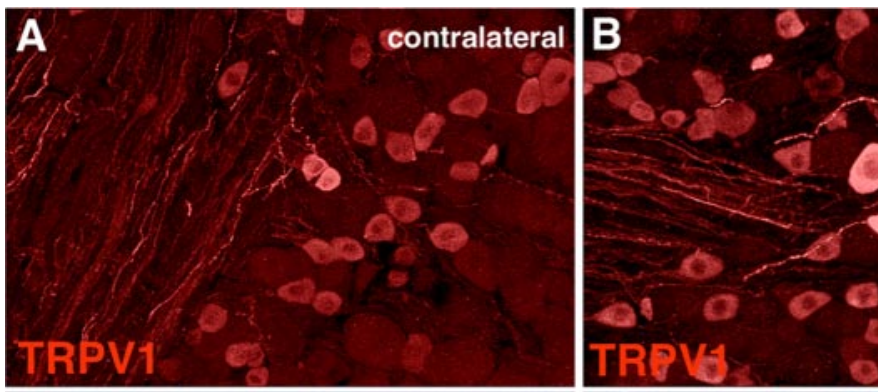

ipsilateral
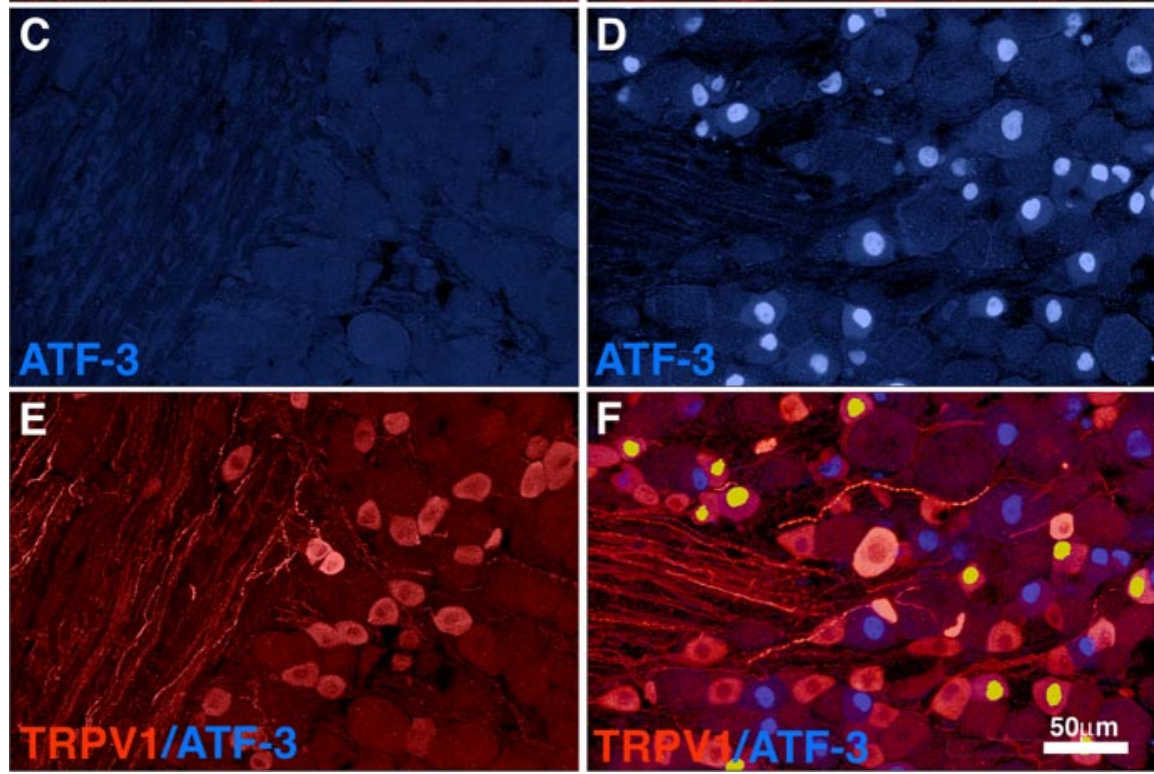

Figure 2. Sensory nerve fibers that innervate the tumor-bearing mouse femur maintain their expression of TRPV1 with disease progression. $\boldsymbol{A}, \boldsymbol{B}, \mathrm{A}$ population of small- to medium-sized neurons in the contralateral DRG normally express the TRPV1 channe when significant hyperalgesia has developed. Fourteen days after tumor injection, tumor cells have invaded the marrow space 列 expressing sensory neurons innervate the tumor-bearing bone and exhibit an iniured phenotype, as demonstrated by ATF-3 coexpression. Moreover, both the percentage of cells expressing TRPV1 1 munoreactivity and their level of TRPV1 were similar in DRG neurons innervating normal and tumor-bearing bone. Scale bar: (in $\boldsymbol{F}$ ) $\boldsymbol{A}-\boldsymbol{F}, 50 \mu \mathrm{m}$.

\section{Discussion}

In the present study, bone cancer-induced ongoing and movement-evoked nocifensive behaviors were reduced after the pharmacologic blockade or genetic deletion of TRPV1. In humans with bone cancer, ongoing pain usually occurs in the area of the tumor and is described as dull, constant, and increasing in intensity over time, with intermittent episodes of extreme pain that occur spontaneously or after weight bearing and/or movement of the affected bone (Coyle et al., 1990; Mercadante and Arcuri, 1998). What is in some ways unique about bone cancer pain is that the inflammation, tumor-released products, and tumor-induced injury to primary afferent neurons may simultaneously drive this chronic pain state (Luger et al., 2001). In the present murine model of bone cancer, mice guarded the affected limb when at rest, when applying weight to the affected bone or during normally non-noxious palpation. All such behaviors were significantly attenuated by TRPV1 blockade or deletion.

There are at least three mechanisms in bone cancer that may contribute to the activation/sensitization of TRPV-1 expressed by sensory fibers that innervate the tumor-bearing bone. In both 

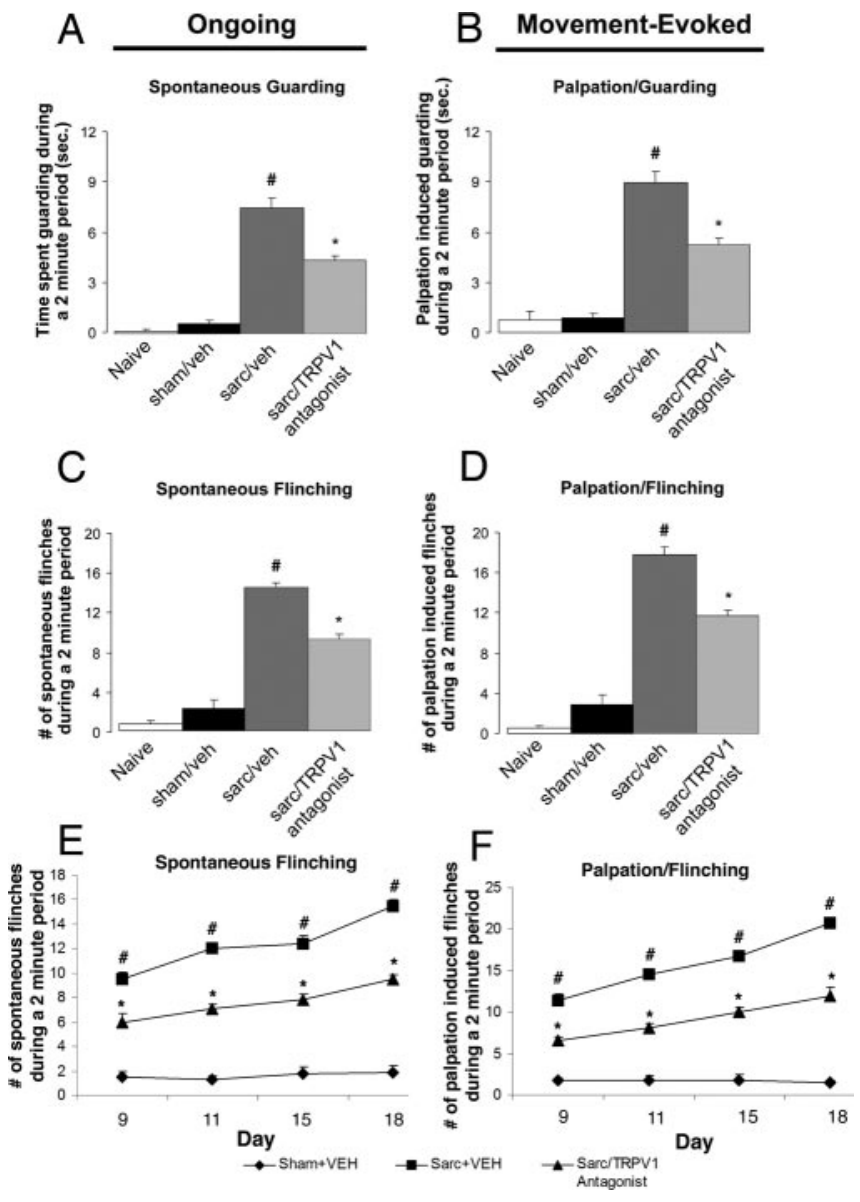

Figure 3. Administration of a TRPV1 antagonist reduces bone cancer-induced pain-related behaviors and retains its analgesic efficacy with disease progression. $A, C$, Tumor-induced ongoing nocifensive behaviors were evaluated by measuring spontaneous guarding $(A)$ and spontaneous flinching $(\boldsymbol{C})$ over a $2 \mathrm{~min}$ observation period. $\boldsymbol{B}, \boldsymbol{D}$, Movement-evoked allodynia was assessed by measuring the time spent guarding $(\boldsymbol{B})$ and flinching $(\boldsymbol{D})$ over a 2 min observation period after normally non-noxious palpation of the distal femur. $A-D$, Note that, in mice with bone cancer, there is a significant increase in the duration and magnitude of guarding $(A, B)$ and flinching $(\boldsymbol{C}, \boldsymbol{D})$. Chronic treatment with the TRPV1 antagonist JNJ-17203212 $(30 \mathrm{mg} / \mathrm{kg}$, S.C.; twice daily), administered from 6 to $18 \mathrm{~d}$ after tumor injection significantly reduced parameters of both ongoing and movement-evoked pain-related behaviors compared with sarcoma (sarc)/ vehicle (veh) animals. $\boldsymbol{E}, \boldsymbol{F}$, Note also that, at all time points examined (days $9-18$ ), chronic administration of JNJ-17203212 (30 mg/kg, s.c.; twice daily) maintained significant analgesic efficacy with disease progression, during which the severity of pain-related behaviors increased. $n>8$ for all experimental categories with the exception of $E, F$, in which $n=4$ for the sarcoma/TRPV1 antagonist group. Error bars represent SEM. ${ }^{\#} p<0.05$, sham/vehicle versus sarcoma/vehicle; ${ }^{*} p<0.05$, sarcoma/TRPV1 antagonist versus sarcoma/vehicle $(\boldsymbol{A}-\boldsymbol{D}$, oneway ANOVA; $E, F$, one-way ANOVA at each time point).

osteolytic (bone-destroying) and osteoblastic (bone-forming) cancers there is a significant proliferation and hypertrophy of osteoclasts (Adami, 1997; Clohisy and Ramnaraine, 1998). Osteoclasts are terminally differentiated, multinucleated, monocyte lineage cells that are uniquely designed to resorb bone by maintaining an extracellular microenvironment of acidic $\mathrm{pH}$ (4.05.0) at the osteoclast-mineralized bone interface (Delaisse and Vaes, 1992). Recent observations in both preclinical models (Yoneda et al., 2000) and humans (Major et al., 2000; Berenson et al., 2001) have demonstrated that osteoclasts play an essential role in cancer-induced bone loss and contribute to the etiology of bone cancer pain. Therapies such as osteoprotegerin or the bisphosphonates, both of which reduce the number of activated osteoclasts (Luger et al., 2001; Sevcik et al., 2004), owe their effi-

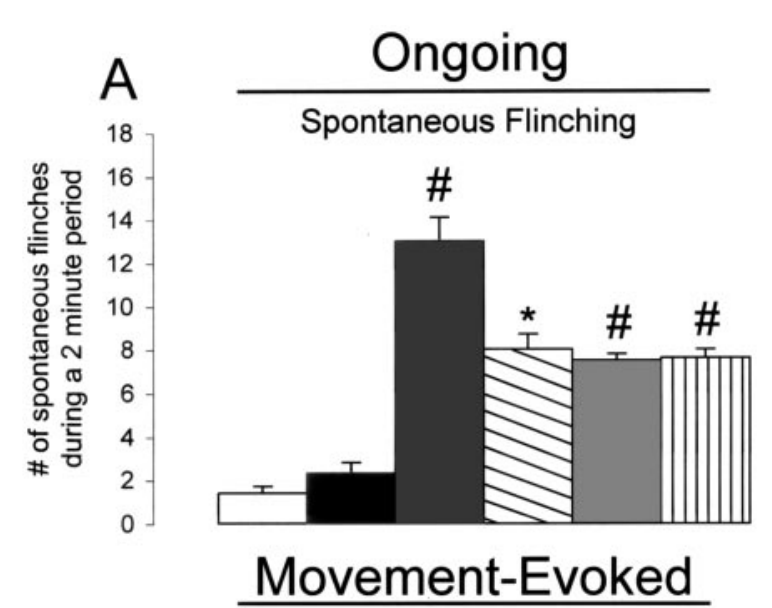

B

Palpation-induced Flinching

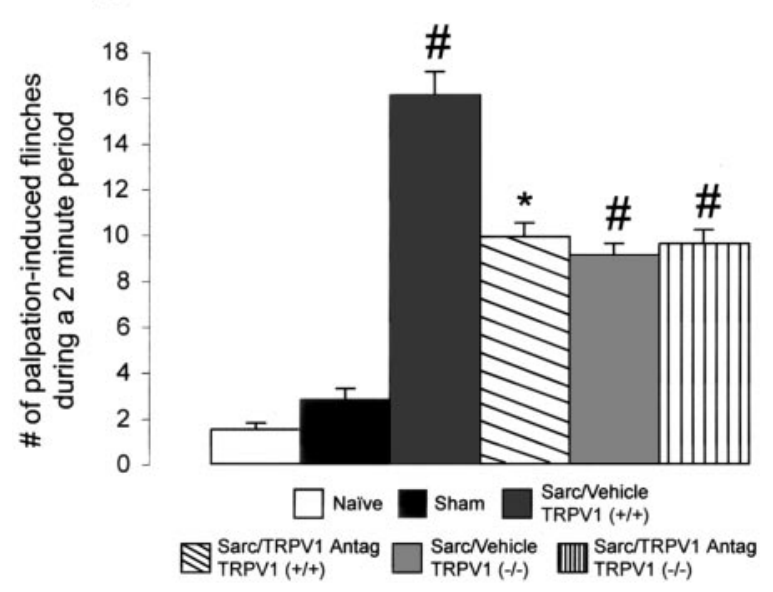

Figure 4. Attenuation of bone cancer-induced pain-related behaviors and lack of additional analgesic effect of a TRPV1 antagonist (Antag) in TRPV1 null mice. $A, B$, Mice lacking a functional TRPV1 show a significant decrease in numbers of ongoing $(\boldsymbol{A})$ and movement-evoked $(\boldsymbol{B})$ painrelated behaviors compared with wild-type $\mathrm{C} 3 \mathrm{H} / \mathrm{HeJ}$ animals when behavioral testing is performed $10-14 \mathrm{~d}$ after tumor injection. Note that the reduction in pain-related behaviors in the TRPV1 null mice is approximately the same as that seen in the tumor-bearing wild-type $\mathrm{C} 3 \mathrm{H} /$ HeJ animals treated with JNJ-17203212 (Fig. 3) and that TRPV1 null mice treated acutely with $30 \mathrm{mg} / \mathrm{kg}$ subcutaneously of JNJ-17203212 showed no additional reduction in pain-related behaviors, suggesting that this compound is exerting its action by antagonizing the TRPV1 channel. Data for naive and sham experimental categories were obtained using TRPV1 ${ }^{+/+}$ bred mice. Error bars represent SEM. ${ }^{*} p<0.05$, versus sham $/$ vehicle; ${ }^{*} p<0.05$, versus sarcoma (sarc)/TRPV1 ${ }^{+/+}$(one-way ANOVA).

cacy in reducing bone cancer pain, at least in part, to the attenuation of osteoclast-mediated acidosis, thereby potentially decreasing proton-induced stimulation of TRPV1 channels on sensory nerve fibers that innervate bone.

Another source of protons that may contribute to TRPV1 stimulation is lysis of tumor cells themselves. Tumor cells have a lower intracellular $\mathrm{pH}$ than normal cells (Griffiths, 1991), and, as a solid tumor outgrows its vascular supply, it becomes necrotic, which may also generate an acidic environment (Reeh and Steen, 1996).

In addition to agents that can directly activate TRPV1, other factors such as bradykinin, ATP, and NGF can modulate TRPV1 function indirectly via activation of second-messenger signaling pathways (Woolf and Salter, 2000; Julius and Basbaum, 2001), resulting in TRPV1 sensitization. Previous studies have shown that these factors can be released from a variety of tumor cells (Drube and Liebmann, 2000; Marchetti et al., 2003; Mujoomdar 
et al., 2003). For example, NGF has been shown to be expressed by many tumor cells and tumor-associated macrophages, including the 2472 sarcoma cells used in the present study (P. W. Mantyh and M. A. Sevcik, unpublished observations). As the bone receives a rich sensory innervation by fibers that express TRPV1, production of these proalgesic agents may also sensitize TRPV1 channels, thereby generating a state of hyperalgesia and/or allodynia (Ji et al., 2002).

Like many chronic pain states, bone cancer pain becomes more severe with disease progression, requiring higher doses of analgesics to control the pain (de Wit et al., 2001). In the present report, we show that administration of a TRPV1 antagonist reduces both bone cancer-induced ongoing and movement-evoked pain-related behaviors and retains this efficacy at early, middle, and late stages of tumor growth. One reason that the antagonism or inactivation of TRPV1 attenuates but does not completely block bone cancer-induced pain behaviors is that other receptors (such as bradykinin, $\mathrm{P}_{2} \mathrm{X}_{3}$, and prostaglandin receptors, or acidsensing ion channel 3 and voltage-gated sodium channels) may also be involved in the generation and maintenance of this pain state (Julius and Basbaum, 2001; Mantyh et al., 2002). The ability of a TRPV1 antagonist to maintain its analgesic potency with disease progression is probably influenced by the fact that sensory nerve fibers innervating the tumor-bearing mouse femur maintain their expression of TRPV1 even as tumor growth and tumorinduced bone destruction progresses. Previous studies suggest that sensory neuronal expression of TRPV1 is upregulated during inflammation (Ji et al., 2002) and downregulated after peripheral nerve injury (Michael and Priestley, 1999). Interestingly, this downregulation of TRPV1 can be blocked by NGF (Priestley et al., 2002). In bone cancer, the peripheral nerve terminals that innervate the bone are injured, indicated by their upregulated expression of ATF-3, a marker of nerve injury (Tsujino et al., 2000; Tsuzuki et al., 2001), but many tumor cells, including the 2472 sarcoma cells used in this model, express NGF (P. W. Mantyh and M. A. Sevcik, unpublished observations), which may help maintain expression of TRPV1 with disease progression. The present results suggest that the TRPV1 channel plays a role in the integration of nociceptive signaling in a severe pain state and that antagonists of TRPV1 may be effective in attenuating difficult-to-treat mixed chronic pain states, such as those encountered in patients with bone cancer pain.

\section{References}

Adami S (1997) Bisphosphonates in prostate carcinoma. Cancer 80:1674-1679.

Berenson JR, Rosen LS, Howell A, Porter L, Coleman RE, Morley W, Dreicer R, Kuross SA, Lipton A, Seaman JJ (2001) Zoledronic acid reduces skeletal-related events in patients with osteolytic metastases. Cancer 91:1191-1200.

Bevan S, Geppetti P (1994) Protons: small stimulants of capsaicin-sensitive sensory nerves. Trends Neurosci 17:509-512.

Caterina MJ, Schumacher MA, Tominaga M, Rosen TA, Levine JD, Julius D (1997) The capsaicin receptor: a heat-activated ion channel in the pain pathway. Nature 389:816-824.

Caterina MJ, Leffler A, Malmberg AB, Martin WJ, Trafton J, Petersen-Zeitz KR, Koltzenburg M, Basbaum AI, Julius D (2000) Impaired nociception and pain sensation in mice lacking the capsaicin receptor. Science 288:306-313.

Clohisy DR, Ramnaraine ML (1998) Osteoclasts are required for bone tumors to grow and destroy bone. J Orthop Res 16:660-666.

Coleman RE (1997) Skeletal complications of malignancy. Cancer 80:1588-1594.

Coleman RE (2001) Metastatic bone disease: clinical features, pathophysiology and treatment strategies. Cancer Treat Rev 27:165-176.

Coyle N, Adelhardt J, Foley KM, Portenoy RK (1990) Character of terminal illness in the advanced cancer patient: pain and other symptoms during the last four weeks of life. J Pain Symptom Manage 5:83-93.

Davis JB, Gray J, Gunthorpe MJ, Hatcher JP, Davey PT, Overend P, Harries MH, Latcham J, Clapham C, Atkinson K, Hughes SA, Rance K, Grau E, Harper AJ, Pugh PL, Rogers DC, Bingham S, Randall A, Sheardown SA (2000) Vanilloid receptor-1 is essential for inflammatory thermal hyperalgesia. Nature 405:183-187.

Dax S, Dubin A, Jetter M, Nasser N, Shah C, Swanson D, Carruthers NI (2002) Vanilloid receptor antagonists: structure activity relationships via parallel and targeted synthesis. Int Symp Med Chem 27:93.

Delaisse J-M, Vaes G (1992) Mechanism of mineral solubilization and matrix degradation in osteoclastic bone resorption. In: Biology and physiology of the osteoclast (Rifkin BR, Gay CV, eds), pp 289-314. Ann Arbor, MI: CRC.

de Wit R, van Dam F, Loonstra S, Zandbelt L, van Buuren A, van der Heijden K, Leenhouts G, Huijer Abu-Saad H (2001) The Amsterdam Pain Management Index compared to eight frequently used outcome measures to evaluate the adequacy of pain treatment in cancer patients with chronic pain. Pain 91:339-349.

Drube S, Liebmann C (2000) In various tumour cell lines the peptide bradykinin $\mathrm{B}(2)$ receptor antagonist, Hoe 140 (icatibant), may act as mitogenic agonist. Br J Pharmacol 131:1553-1560.

Griffiths JR (1991) Are cancer cells acidic? Br J Cancer 64:425-427.

Honore P, Menning PM, Rogers SD, Nichols ML, Mantyh PW (2000a) Neurochemical plasticity in persistent inflammatory pain. Prog Brain Res 129:357-363.

Honore P, Luger N, Sabino M, Schwei M, Rogers S, Mach D, O'Keefe P, Ramnaraine M, Clohisy D, Mantyh P (2000b) Osteoprotegerin blocks bone cancer-induced skeletal destruction, skeletal pain and pain-related neurochemical reorganization of the spinal cord. Nat Med 6:521-528.

Hunt SP, Pini A, Evan G (1987) Induction of $c$-fos-like protein in spinal cord neurons after sensory stimulation. Nature 328:632-634.

Ji RR, Samad TA, Jin SX, Schmoll R, Woolf CJ (2002) p38 MAPK activation by NGF in primary sensory neurons after inflammation increases TRPV1 levels and maintains heat hyperalgesia. Neuron 36:57-68.

Julius D, Basbaum AI (2001) Molecular mechanisms of nociception. Nature 413:203-210.

Luger NM, Honore P, Sabino MAC, Schwei MJ, Rogers SD, Mach DB, Clohisy DR, Mantyh PW (2001) Osteoprotegerin diminishes advanced bone cancer pain. Cancer Res 61:4038-4047.

Krishtal OA, Pidoplichko VI (1980) A receptor for protons in the nerve cell membrane. Neuroscience 5:2325-2327.

Mach DB, Rogers SD, Sabino MAC, Luger NM, Schwei MJ, Pomonis JD, Keyser CP, Clohisy DR, Adams DJ, O'Leary P, Mantyh PW (2002) Origins of skeletal pain: sensory and sympathetic innervation of the mouse femur. Neuroscience 113:155-166.

Major PP, Lipton A, Berenson J, Hortobagyi G (2000) Oral bisphosphonates: a review of clinical use in patients with bone metastases. Cancer 88:6-14.

Mantyh PW, Clohisy DR, Koltzenburg M, Hunt SP (2002) Molecular mechanisms of cancer pain. Nat Rev Cancer 2:201-209.

Marchetti D, Denkins Y, Reiland J, Greiter-Wilke A, Galjour J, Murry B, Blust J, Roy M (2003) Brain-metastatic melanoma: a neurotrophic perspective. Pathol Oncol Res 9:147-158.

Mercadante S, Arcuri E (1998) Breakthrough pain in cancer patients: pathophysiology and treatment. Cancer Treat Rev 24:425-432.

Michael GJ, Priestley JV (1999) Differential expression of the mRNA for the vanilloid receptor subtype 1 in cells of the adult rat dorsal root and nodose ganglia and its downregulation by axotomy. J Neurosci 19:1844-1854.

Mujoomdar M, Hoskin D, Blay D (2003) Adenosine stimulation of the proliferation of colorectal carcinoma cell lines. Biochem Pharmacol 66:1737-1747.

Portenoy RK, Payne D, Jacobsen P (1999) Breakthrough pain: characteristics and impact in patients with cancer pain. Pain 81:129-134.

Priestley JV, Michael GJ, Averill S, Liu M, Willmott N (2002) Regulation of nociceptive neurons by nerve growth factor and glial cell line derived neurotrophic factor. Can J Physiol Pharmacol 80:495-505.

Reeh PW, Steen KH (1996) Tissue acidosis in nociception and pain. Prog Brain Res 113:143-151.

Sabino MAC, Ghilardi JR, Jongen JL, Keyser CP, Luger NM, Mach DB, Peters CM, Rogers SD, Schwei MJ, de Felipe C, Mantyh PW (2002) Simulta- 
neous reduction in cancer pain, bone destruction, and tumor growth by selective inhibition of cyclooxygenase-2. Cancer Res 62:7343-7349.

Schwei MJ, Honore P, Rogers SD, Salak-Johnson JL, Finke MP, Ramnaraine ML, Clohisy DR, Mantyh PW (1999) Neurochemical and cellular reorganization of the spinal cord in a murine model of bone cancer pain. J Neurosci 19:10886-10897.

Sevcik MA, Luger NM, Mach DB, Sabino MAC, Peters CM, Ghilardi JR, Schwei MJ, Rohrich H, De Felipe C, Kuskowski MA, Mantyh PW (2004) Bone cancer pain: the effects of the bisphosphonate alendronate on pain, skeletal remodeling, tumor growth and tumor necrosis. Pain 111:169-180.

Tominaga M, Caterina MJ, Malmberg AB, Rosen TA, Gilbert H, Skinner K, Raumann BE, Basbaum AI, Julius D (1998) The cloned capsaicin receptor integrates multiple pain-producing stimuli. Neuron 21:531-543.
Tsujino H, Kondo E, Fukuoka T, Dai Y, Tokunaga A, Miki K, Yonenobu K, Ochi T, Noguchi K (2000) Activating transcription factor 3 (ATF3) induction by axotomy in sensory and motoneurons: a novel neuronal marker of nerve injury. Mol Cell Neurosci 15:170-182.

Tsuzuki K, Kondo E, Fukuoka T, Yi D, Tsujino H, Sakagami M, Noguchi K (2001) Differential regulation of P2X(3) mRNA expression by peripheral nerve injury in intact and injured neurons in the rat sensory ganglia. Pain 91:351-360.

Woolf CJ, Salter MW (2000) Neuronal plasticity: increasing the gain in pain. Science 288:1765-1769.

Yoneda T, Michigami T, Yi B, Williams PJ, Niewolna M, Hiraga T (2000) Actions of bisphosphonate on bone metastasis in animal models of breast carcinoma. Cancer 88:2979-2988. 